\title{
Avaliação Estrutural das Opções Existentes para Implantação de Mezaninos Metálicos e sua Influência na Capacidade Portante da Estrutura de Concreto Existente
}

\author{
PANTOJA, João da Costa ${ }^{1}$ \\ PINTO, Ricardo Luiz Ferreira ${ }^{2}$ \\ NARVAEZ, Nathaly Sarasty ${ }^{3}$ \\ OLIVEIRA, Ana Luiza Alves de ${ }^{4}$
}

\begin{abstract}
${ }^{1}$ Universidade de Brasília, Brasil. joaocpantoja@gmail.com ${ }^{2}$ Centro Universitário de Brasília, Brasil. ricardo.sol@terra.com.br ${ }^{3}$ Centro Universitário de Brasília, Brasil. nathalysarasty@hotmail.com ${ }^{4}$ Centro Universitário de Brasília, Brasil. alves.analuiza@hotmail.com
\end{abstract}

\begin{abstract}
Resumo
Projetos de reforço estrutural requerem um grande cuidado tanto dos projetistas quando dos executores, uma vez que ao fazê-lo, não se deve deteriorar a estrutura já existente, que estiver em boas condições. Neste estudo foram avaliadas as condições da estrutura de um local que, futuramente, seria a Casa de Diversões HOG CLUB, onde três mezaninos seriam instalados para aumentar a sua área útil. Em seguida, foi realizada uma avaliação da influência desses mezaninos na capacidade portante da estrutura de concreto já existente no local e escolhida a melhor opção para a sua instalação. Enfim, o projeto estrutural dessa implantação foi realizado.
\end{abstract}

Palavras-chave: reforço estrutural, mezanino, estruturas metálicas.

\begin{abstract}
Structural reinforcement projects require great care from the designers and from the executors, since by doing so, it should not damage the existing structure that is in good condition. This study has analyzed the conditions of the structure of a location that in the future would be the HOG CLUB Fun House, where three mezzanines would be installed to increase its service area. Then an evaluation of the influence of these mezzanines at the bearing capacity of the existing concrete structure was held, and the best option for its installation was chosen. Finally, the structural design of this deployment was made.
\end{abstract}

Key Words: structural reinforcement, mezzanine, metal structures. 


\section{Introdução}

Reforço estrutural consiste na alteração das características da estrutura existente buscando a recomposição da capacidade inicial de projeto e/ou adequá-la a novos parâmetros devido a mudança e/ou aumento das cargas atuantes. Esse ato requer a utilização de softwares especializados e de profissionais capacitados.

Foi exatamente essa a situação que ocorreu para que a Casa de Diversões Hog Club, localizada no térreo do Bloco A do Centro Empresarial Brasil XXI no Setor Hoteleiro Sul de Brasília (DF), estivesse apropriada para os seus fins. A Figura 01 mostra a planta baixa do local na edificação.

Figura 01: Localização da Hog Club

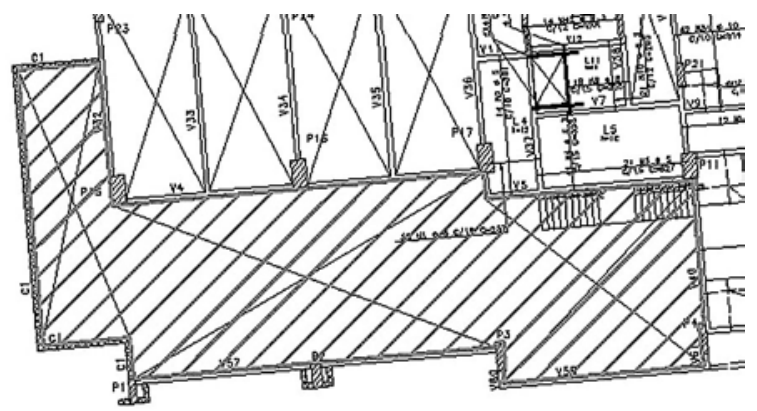

Esse centro empresarial teve a sua estrutura projetada e construída no início dos anos 2000, com uma estrutura mista de concreto armado, protendido e estruturas metálicas, e possui $200.000 \mathrm{~m}^{2}$ de área construída.

A princípio, na área, existia apenas a laje do piso e do teto com um pé-direito duplo, e as paredes feitas em alvenaria. Ademais, existia também vigas de fechamento lateral, executadas em um nível intermediário dos pavimentos, conforme a figura 02.

Figura 02: Local antes da instalação dos mezaninos

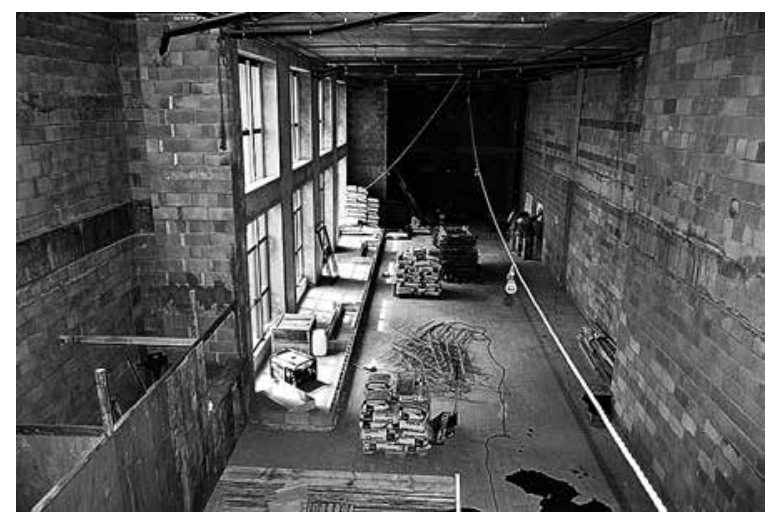

Fora solicitado que três mezaninos metálicos fossem instalados conforme a área mostrada na Figura 03. A principal função desses mezaninos é a de servir como piso e, consequentemente, aumentar a área útil do empreendimento.

Um deles está localizado na entrada do ambiente, que é o Mezanino 1. O Mezanino 2 fica virado para o salão principal. Já o Mezanino 3 está localizado no final do ambiente, conforme a Figura 03. Neles estavam localizados os lounges e banheiros da casa de diversões.

A Figura 03 abaixo também mostra as vigas e pilares já existentes no local antes da intervenção realizada, com suas respectivas nomenclaturas.

Desses elementos estruturais, as principais vigas analisadas e que foram reforçadas para receber esse novo esforço foram as C1, V4, V40, V 58. Já os pilares mais estudados foram os P15, P16 e P17.

Figura 03: Localização dos mezaninos instalados

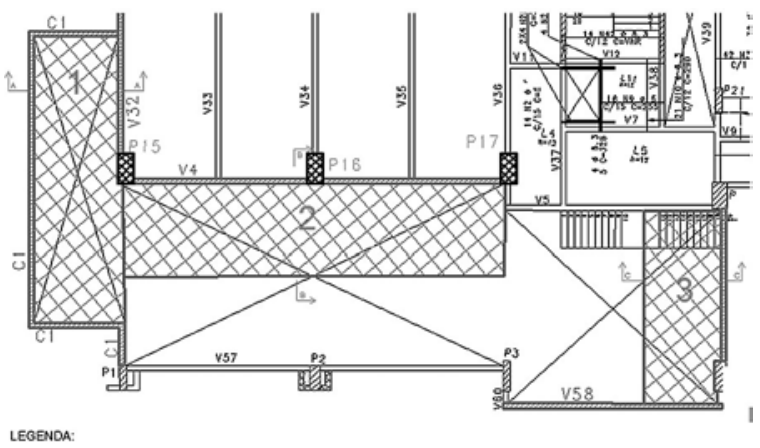

QD LOCAUZAGĞO DOS MEZANINOS PLLARES REFORGADOS VIGAS REFORGAOAS

Observou-se também que as vigas de concreto armado existentes para apoio dos mezaninos têm as seguintes características:

Altura $(A)=50 \mathrm{~cm}$;

Base $(B)=20 \mathrm{~cm}$;

Seção $(S)=1000 \mathrm{~cm}^{2}$;

Momento de inércia vertical $(I x)=208.333,3 \mathrm{~cm}^{4}$;

Módulo de resistência à flexão $(W x)=8.333,33$ $\mathrm{cm}^{3}$;

Módulo de elasticidade do aço $(\mathrm{E})=210 \mathrm{GPa}$.

A Figura 04 a seguir mostra melhor a proposta arquitetônica e de design de interiores dos mezaninos no local. 
Figura 04: Projeto arquitetônico do HOG CLUB

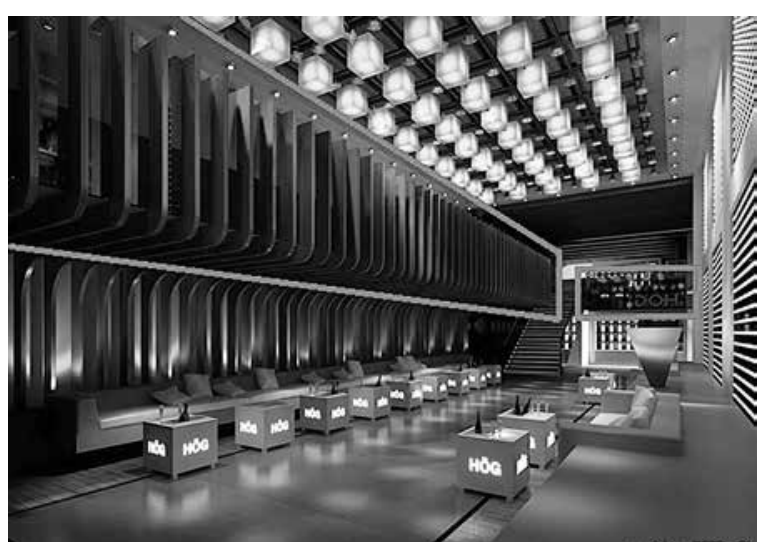

\section{Vistoria}

Antes de começar a estudar as possibilidades existentes para a instalação dos mezaninos desejados, uma vistoria foi realizada. Através de uma análise visual e de uma consulta sucinta aos projetos existentes, pode-se chegar às seguintes observações:

- O aço empregado foi o CA 50, com tensão resistente à tração característica de $500 \mathrm{MPa}$;

- As cordoalhas engraxadas utilizadas na estrutura foram do tipo CP 190 - RB;

- A resistência característica à compressão do concreto foi de $30 \mathrm{MPa}$ para pilares, vigas e lajes;

- Não existem fissuras ou trincas visíveis nas fachadas, nem no interior do prédio.

Portanto, pode-se afirmar que a estrutura encontrava-se em um ótimo estado, sem sintomas de carga excessiva ou de desgaste de quaisquer de suas peças.

\section{Soluções Estruturais}

Para a instalação do mezanino 2, que é o principal pois possuía o maior balanço e receberia a maior carga, foram apresentadas três possíveis soluções estruturais a serem analisadas.

Proposta 1: os apoios principais seriam fixados através de dois perfis nos pilares de concreto armados existentes;

Proposta 2: os apoios principais seriam engastados nas vigas laterais;

Proposta 3: as fixações seriam feitas via três pórticos planos que seriam fixados aos pilares existentes.

\section{Metodologia de análise}

Os seguintes documentos foram analisados para efetuar a implantação do mezanino:

- Projeto estrutural do bloco A do Centro Empresarial Brasil XXI, que indica as posições e dimensões das vigas e pilares existentes e suas armações;

- Projeto estrutural de estrutura metálica dos mezaninos, com as três opções propostas, possibilitando avaliar os pontos onde as cargas adicionais irão influir;

- Projeto arquitetônico do HOG CLUB, para que fosse feita a compatibilidade com a estrutura e cargas atuantes sobre lajes e vigas.

Com base nesses documentos, as seguintes avaliações foram realizadas:

- Levantamento do peso total das alvenarias e lajes existentes;

- Identificação dos pilares e pontos de fundação afetados pelo acréscimo da carga dos mezaninos;

- Verificação do percentual de acréscimo de carga decorrente da implantação dos mezaninos e análise de suas consequências;

- Identificação das vigas que receberam os acréscimos de carga mais significativos e de suas dimensões;

Verificação das vigas mais carregadas considerando a situação antes e após a execução dos mezaninos, quanto aos Estados Limites Últimos e análise dos resultados.

Para verificar a influência das novas cargas em um prédio já construído, a rigor, ter-se-ia que recalcular toda a estrutura. No entanto, essa solução apresenta dificuldades e inconvenientes, dentre os quais se destacam:

- A dificuldade de se adotar, no recálculo, as mesmas hipóteses e critérios de carregamento, cálculos de esforços e dimensionamentos adotados pelo projetista original, tornando a comparação duvidosa;

- O custo de se recalcular a estrutura seria equivalente à elaboração de um novo projeto estrutural.

Portanto, a solução adotada foi a de identificar as partes ou peças que serão efetivamente afetadas pela nova situação de carga, verificando-as isoladamente. Para isso, algumas hipóteses de cálculo foram adotadas: 
- $1^{\text {a }}$ Hipótese: as vigas de concreto existentes funcionam apoiadas ou semi-engastadas nos pilares da estrutura;

- $2^{a}$ Hipótese: foram desconsideradas as contribuições das paredes estruturais de apoio existentes. Isso foi feito de forma a compatibilizar a estrutura modelada com as hipóteses de estrutura original, acarretando numa reserva de segurança aos Estados Limites Ultimos (ELU) e Estados Limites de Serviço (ELS).

- $3^{\mathrm{a}}$ Hipótese: a estrutura original cumpre todos os requisitos para qual foi projetada. Nenhum ensaio ou verificação foi executado para essa confirmação.

- $4^{a}$ Hipótese: devido à baixa influência dos esforços envolvidos na implantação dos mezaninos, não houve necessidade de verificar os pontos de fundações existentes.

- $5^{a}$ Hipótese: as cargas resultantes dos mezaninos recairiam diretamente sobre os pilares e vigas transversais na forma de cargas concentradas e distribuídas.

Assim, pode-se constatar que a Proposta 2 geraria excessivos esforços de torção nas vigas, sendo a pior opção. A Proposta 1 também foi descartada pois leva a um sistema menos seguro e com maior probabilidade de falha ao transferir grandes esforços aos pilares de concreto existentes. Sendo assim, a Proposta 3 foi a escolhida pois um sistema de pórticos distribui os carregamentos de uma maneira mais eficiente, sem sobrecarregar os pilares.

\section{Projeto de reforço estrutural}

O reforço estrutural escolhido foi o da Proposta 3, que é constituído por um sistema com três pórticos metálicos. Para esses cálculos, não se considerou o trabalho conjunto dos pilares e vigas existentes, o que alivia consideravelmente as tensões existentes e tem efeito principalmente na redução das deformações (flechas). Esse aspecto age como um coeficiente de segurança extra para a estrutura.

Primeiramente foi feito um projeto de reforço a cisalhamento e flexão nas vigas de apoio de concreto armado, (V4, C1, V32 e V40) devido ao acréscimo de cargas com a implantação dos mezaninos metálicos.

Para o reforço, foi adotado o uso de pórticos fixados nos pilares da estrutura de concreto armado, (P15, P16 e P17) como apoio principal para o mezanino. Isso levou a um sistema de fixação com mais pontos, diminuindo a probabilidade de falha do sistema estrutural. Também acarretou em um aumento da rigidez do mezanino, ajudando na verificação dos Estados Limites de Serviço (ELS) relacionados à vibrações e deformações.

A seguir, uma explicação mais detalhada será dada sobre o projeto metálico de cada um dos mezaninos.

\section{- Mezanino 1}

Esse mezanino está a três metros de altura e é composto por vigas bi-apoiadas de perfis metálicos W $200 \times 15$. A sua ligação com a viga $C 1$ foi

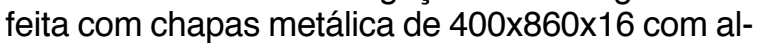
hetas. Já com a viga V32, por possuir uma altura diferente da $\mathrm{C} 1$, essa ligação foi feita com chapas metálicas de $300 \times 651 \times 16$ que também possuíam alhetas para deixar essa ligação rígida. A Figura 06 mostra o corte com o esquema de como foi feito o mezanino.

Figura 06: Corte mezanino 1

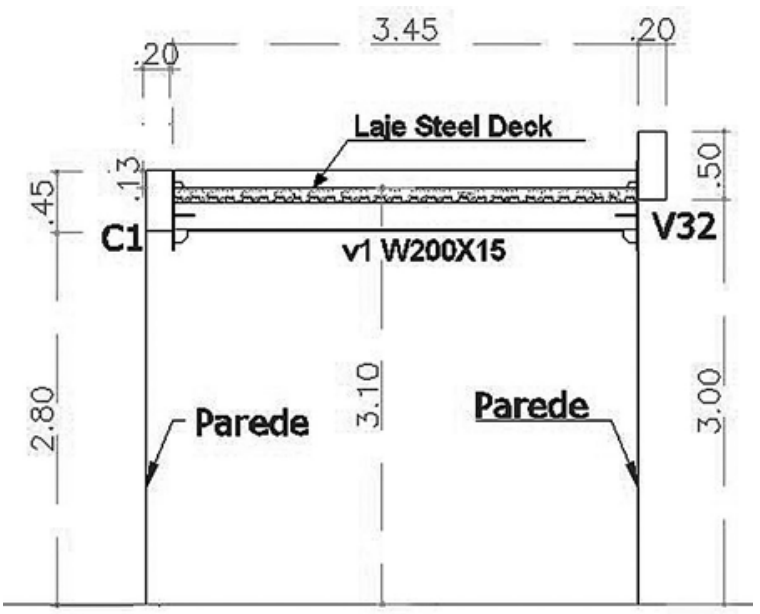

- Mezanino 2

Esse mezanino foi o mais complexo de ser realizado, uma vez que ele não podia estar ancorado na viga $V 4$, pois isso causaria uma grande torção e traria prejuízos à estrutura do local.

A solução encontrada para esse mezanino foi a de se fazer um pórtico constituído de vigas metálicas com perfil W 460 x 60 e três pilares metálicos que possuem o mesmo perfil das vigas (W $460 \times 60)$.

Esses pilares metálicos estão ancorados aos três pilares de concreto armado previamente existentes (P15, P16 e P17) e não estão apoiados na laje do pavimento inferior, uma vez que ela é protendida e não poderia ser perfurada. As ligações entre os pilares metálicos e os de concreto foram realizadas usando chapas metálicas de 391 x 400 x 16 com alhetas.

A Figura 07 apresenta o corte no mezanino 2 mostrando a sua ligação com o pilar de concreto. 
Figura 07: Corte mezanino 2

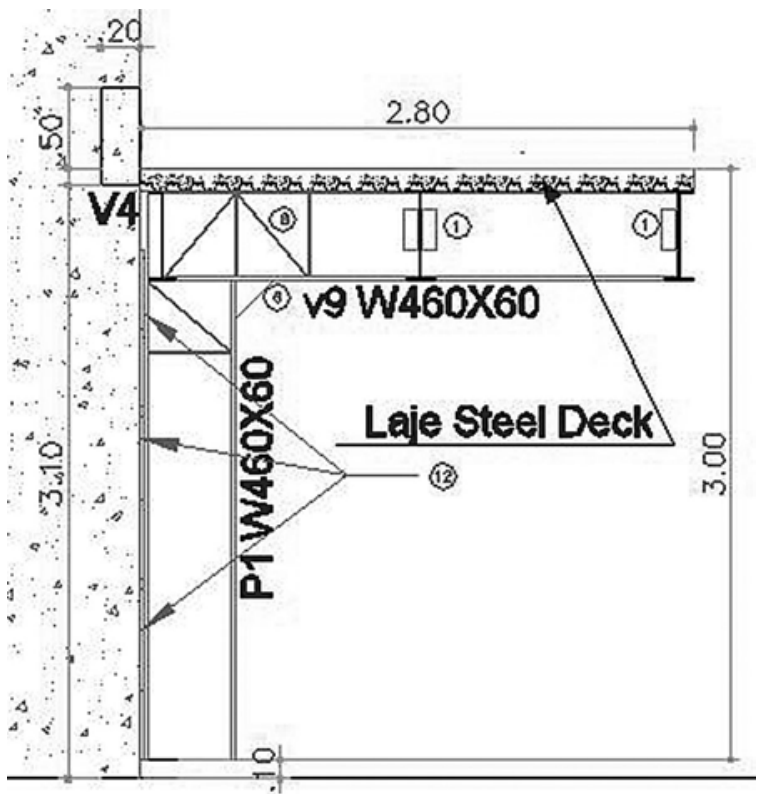

Na Figura 7, são destacados alguns elementos estruturais auxiliares. São estes:

1: Ligação entre vigas perpendiculares entre si;

6: Alheta de reforço à flexão;

8: Enrijecedor para a viga na ligação com o pilar;

12: Chapas de ligação do pilar metálico ao de concreto. Essas chapas estão representadas na Figura 08, sendo que a primeira representa a chapa ligada ao $\mathrm{P} 16$, e a segunda aos P15 e P17.

Figura 08: Chapas de ligação do pilar metálico ao de concreto
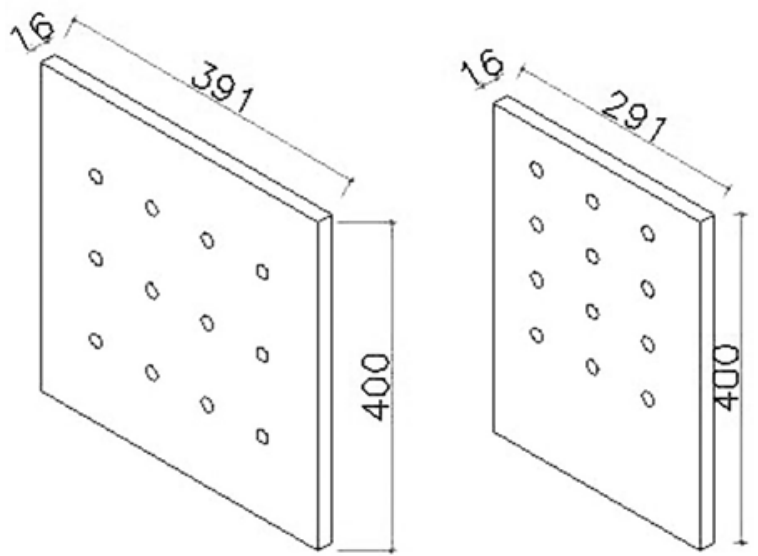

- Mezanino 3

Para o mezanino 3, foram usadas cinco vigas metálicas com o perfil W 200 x 15 . Essas vigas foram ligadas à viga de concreto já existente com uma chapa de $300 \times 651 \times 16$ $\mathrm{mm}$ com alhetas.

A Figura 09 a seguir representa o corte da estrutura desse mezanino.

Figura 09: Corte mezanino 3

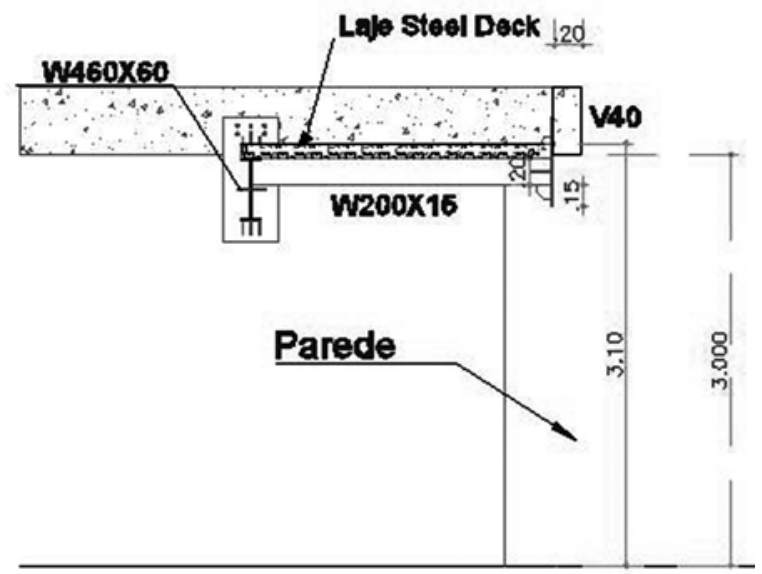

- Lajes

As lajes dos mezaninos foram realizadas utilizando o sistema steel deck METFORM MF 50, com uma espessura de $110 \mathrm{~mm}$ incluindo a camada de concreto. Foi utilizada uma malha eletrosoldada Q-75, Ф3,8 x Ф3,8 $-150 \times 150$.

Foram empregados também pinos conectores de cortante com diâmetro de $19 \mathrm{~mm}$ e comprimento de $80 \mathrm{~mm}$, para fixação da laje. A Figura 10 abaixo mostra um corte de como foi utilizada a laje.

Figura 10: Laje steel deck utilizada

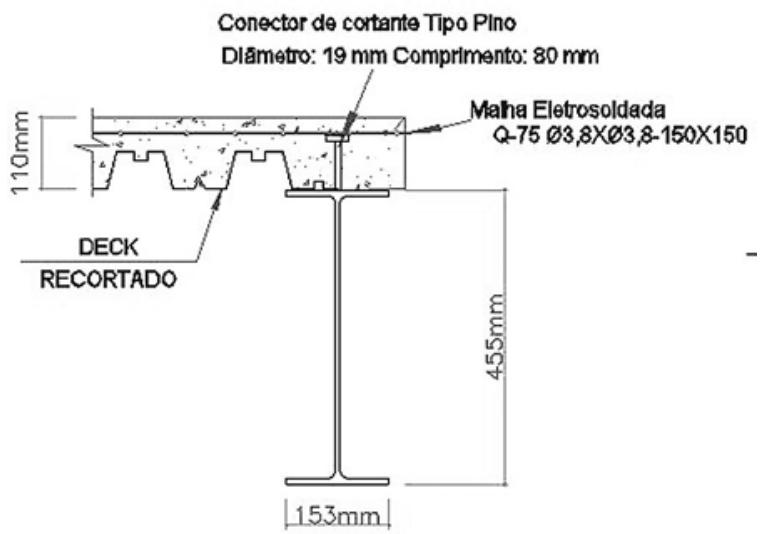




\section{Conclusão}

Cada um dos mezaninos teve a sua estrutura calculada de forma que houvesse o melhor custobenefício para o cliente. Para o mezanino 2, que era o mais complexo, três opções para a sua instalação foram analisadas.

A $1^{\text {a }}$ opção era a de fazer os apoios principais fixados através de dois perfis nos pilares de concreto armado. A segunda era a de fazer os apoios principais engastados nas vigas laterais. Enfim, a $3^{\mathrm{a}}$ opção foi escolhida, que consistia em fazer fixações que seriam feitas via três pórticos planos que seriam fixados aos pilares de concreto armado já existentes. Após calcular a estrutura, esses mezaninos foram executados e o objetivo do trabalho cumprido.

\section{Referências Bibliográficas}

SILVA, L. S.; GERVÁSIO, H. Manual de Dimensionamento de Estruturas Metálicas: Métodos Avançados. Ed. CMM - Associação Portuguesa de Construções Metálicas e Mista. 2007.

PINHEIRO, A. C. F. B.; Estruturas Metálicas - Cálculos, detalhes, exercícios e projetos. Ed. Edgard Blucher Ltda. São Paulo, 2001.

CARVALHO, P. R. M.; GRIGOLETTI, G.; BARBOSA, G. D. Curso básico de perfis de aço formados a frio. $3^{\text {a }}$ Edição. Porto Alegre, 2014. 